\title{
The Effects of Frequent Electroejaculation on the Semen Characteristics of a Captive Siberian Tiger (Panthera tigris altaica)
}

\author{
Daisuke FUKUI 1)\#*, Masashi NAGANO2)*, Ryohei NAKAMURA'), Gen BANDO' ${ }^{1)}$, \\ Shinichi NAKATA ${ }^{1)}$, Masao KOSUGE'), Hideyuki SAKAMOTO' ${ }^{3)}$, Motozumi MATSUI ${ }^{4)}$, \\ Yojiro YANAGAWA ${ }^{2)}$ and Yoshiyuki TAKAHASHI ${ }^{2)}$ \\ 1) Asahikawa Municipal Asahiyama Zoological Park \& Wildlife Conservation Center, Asahikawa 078-8205, Japan \\ ${ }^{2)}$ Laboratory of Theriogenology, Graduate School of Veterinary Medicine, Hokkaido University, Sapporo 060-0818, Japan \\ 3) Noboribetsu Bear Park, Noboribetsu 059-0551, Japan \\ ${ }^{4)}$ Division of Preventive Medicine, Department of Applied Veterinary Medicine, Obihiro University of Agriculture and \\ Veterinary Medicine, Obihiro 080-8555, Japan \\ \#Present: Department of Small Animal Clinical Sciences, School of Veterinary Medicine, Rakuno Gakuen University, \\ Hokkaido 069-8501, Japan
}

\begin{abstract}
Artificial insemination (AI) can help to avoid inbreeding and genetic degeneration for sustaining genetically healthy populations of endangered species in captivity. Collection of a sufficient quantity of viable sperm is an essential first step in the AI process. In the present study, we examined the effects of frequent electroejaculation on semen characteristics in a Siberian tiger. We collected semen in all 17 trials during 6 breeding seasons (6 years). The mean number of sperm and the percentage of motile sperm were $294.3 \pm 250.2 \times 10^{6} /$ ejaculate and $82.4 \pm 11.4 \%$, respectively. The number of motile sperm tended to increase during frequent electroejaculation in the same breeding season. Semen collection by electroejaculation can be performed effectively up to the fourth sequential ejaculate, which contained the most sperm in the study. In conclusion, frequent collection of sperm by electroejaculation from tigers may be effective for collection of a large number of motile sperm.
\end{abstract}

Key words: Frequent electroejaculation, Semen quality, Tiger

(J. Reprod. Dev. 59: 491-495, 2013)

$\mathbf{T}$ he Siberian tiger (Panthera tigris altaica) is a critically endangered species, and the wild population is estimated to be approximately 360 individuals in the world according to a report of the International Union for Conservation of Nature and Natural Resources in 2011 [1]. On the other hand, zoos throughout the world maintain 466 Siberian tigers in captivity [2]. Therefore, it is necessary for zoos to develop effective reproduction methods and contribute to ex situ conservation for the Siberian tiger. In domestic animals, artificial insemination (AI) is usually used commercially. The AI technique can help to avoid inbreeding and genetic degeneration for sustaining a genetically healthy population of Siberian tiger, because it makes it possible to transfer genes among populations. But the success rate of AI remains inconsistent for many wild felidae including the tiger [3]. Although a great deal of effort has been made to develop AI methods in the tiger $[4,5]$, only three pregnancies have been reported by two research groups using laparoscopic intrauterine $[6$, 7] and intravaginal AI [8]. In the domestic cat, it was clarified that the sperm number required in fresh semen for pregnancy was $8 \times 10^{6}$

Received: February 6, 2013

Accepted: May 16, 2013

Published online in J-STAGE: June 16, 2013

(C)2013 by the Society for Reproduction and Development

Correspondence: D Fukui (e-mail: blood@d3.dion.ne.jp)

*D Fukui and M Nagano contributed equally to this work. for intrauterine AI [9] and $80 \times 10^{6}$ for intravaginal AI [10]. In the tiger, intrauterine AI using $62.5-340 \times 10^{6}$ motile sperm for 9 tigers resulted in no pregnancy [4], although offspring were obtained using $16.8 \times 10^{6}$ (intrauterine) [6] and $500 \times 10^{6}$ motile sperm (intravaginal) [8]. Although the optimal number of sperm for pregnancy by AI in the tiger is not clear, studies concerning improvement of the semen collection protocol to obtain as many viable sperm as possible in order to achieve successful AI are necessary.

To obtain semen in the tiger, the electroejaculation method developed by a research group at the Smithsonian's National Zoological Park $[5,11]$ has been used in many reports $[4,6,8,12-18]$. However, the quantity and quality of semen collected by this method from 14 males (23 ejaculates) were variable as follows: seminal volume, 0.8 to $14.0 \mathrm{ml}$; number of motile sperm, 2.2 to $644.0 \times 10^{6}$; motility of sperm, 50 to $90 \%$; abnormality of sperm, 8.0 to $91.0 \%$ [5]. This electroejaculation regimen was composed of 3-stimulus series using 3 to $6 \mathrm{~V}[5,11]$. Therefore, semen could be collected as several ejaculates by this regimen. However, the ejaculation pattern and characteristics of each ejaculate were not reported. In the domestic cat, it has been reported that the volume and the number of sperm were different in each ejaculate when electroejaculation with stepwise increases in voltage (1, 2, 4 and $8 \mathrm{~V}$ ) was used [19], and that the semen volume increased as the electroejaculation trial was repeated [20].

In the present study, we tried to collect semen from a male Siberian tiger during 6 breeding seasons (2002 to 2008). To clarify the changes 
Table 1. Semen characteristics collected by electroejaculation and the effect of urine contamination on the sperm quality in a Siberian tiger

\begin{tabular}{|c|c|c|c|}
\hline \multirow{2}{*}{ Items } & \multirow{2}{*}{$\begin{array}{l}\text { Mean semen characteristics* } \\
\qquad(\mathrm{n}=17)\end{array}$} & \multicolumn{2}{|c|}{$\begin{array}{l}\text { Semen characteristics without or with urine contamination } \\
\text { collected in a same trial }(n=4)\end{array}$} \\
\hline & & - & + \\
\hline Volume (ml) & $5.8 \pm 2.7(2.3-11.5)$ & $3.7 \pm 1.3(2.7-5.7)$ & $5.1 \pm 2.2(3.0-8.1)$ \\
\hline $\mathrm{pH}$ & $7.5 \pm 0.2(7.2-7.8)$ & $7.5 \pm 0.1^{\mathrm{a}}(7.4-7.6)$ & $6.4 \pm 0.2^{\mathrm{b}}(6.2-6.5)$ \\
\hline No. of sperm $\left(\times 10^{6}\right.$ cells /ejaculate $)$ & $294.3 \pm 250.2(13.8-1027.7)$ & $241.5 \pm 200.9(34.0-473.1)$ & $85.3 \pm 49.8(25.8-145.0)$ \\
\hline No. of motile sperm $\left(\times 10^{6}\right.$ cells /ejaculate $)$ & $255.6 \pm 252.3(9.7-919.8)$ & $207.1 \pm 169.0(30.6-400.7)$ & $33.4 \pm 27.9(5.2-63.3)$ \\
\hline$\%$ of motile sperm & $82.4 \pm 11.4(50.0-95.0)$ & $87.3 \pm 2.6^{\mathrm{a}}(84.7-90.0)$ & $41.1 \pm 30.5^{\mathrm{b}}(10.0-70.0)$ \\
\hline$\%$ of live sperm ${ }^{* *}$ & $86.3 \pm 11.3(54.0-98.5)$ & $89.7 \pm 6.5(84.5-97.0)$ & $60.5(54.5-66.5)$ \\
\hline$\%$ of morphologically normal sperm & $91.2 \pm 3.5(86.0-96.5)$ & NE & NE \\
\hline
\end{tabular}

Values are means \pm SD (ranges). ${ }^{a, b}$ Values with different superscript differ significantly $(\mathrm{P}<0.05)$. Values are calculated from semen excluded the ejaculates with urine contamination. ** Samples without and with urine contamination ( 3 and 2, respectively) are examined. NE: not examined.

in the characteristics of semen in each ejaculate and within/between reproductive seasons, we examined the sperm number and quality, testicular volume and serum testosterone and cortisol concentrations. For collecting sperm with good quality, urine contamination, which is known to cause a decrease in sperm quality [21], is a common problem in the cat $[19,20]$ and tiger [11]. To avoid urine contamination or decrease its effects, we drained urine before electroejaculation and replaced it with Ham's F10 medium.

In all 17 trials during the 6 breeding seasons, we could collect semen from a male tiger. Each trial included 2 to 6 ejaculates of semen. As shown in Table 1, the characteristics of the collected semen without urine contamination were within the range described by Wildt et al. [5] and similar to mean values reported by Howard [11]. The influence of tiger age on spermatogenesis was not observed in the present study, since a large quantity of viable sperm $\left(267.2 \times 10^{6}\right)$ was obtained at 11 years of age in February, 2008 (Fig. 1). There were no obvious relationships between testicular volume, steroid hormone concentrations and semen characteristics in the present study. The testicular volume during the experimental period was within the range (22.6 to $41.5 \mathrm{~cm}^{3}$ ) reported previously [5]. The mean concentration of serum testosterone and cortisol were $1.9 \mathrm{ng} / \mathrm{ml}$ (range: 1.2 to 4.4 $\mathrm{ng} / \mathrm{ml}$ ) and $22.6 \mathrm{ng} / \mathrm{ml}$ (range: 15.6 to $30.1 \mathrm{ng} / \mathrm{ml}$ ), respectively. The concentration of serum testosterone was similar to those reported in the previous studies $[17,22]$, and the serum cortisol level was lower than that in a previous study [22]. Our results indicate that the frequent anesthesia and electrical stimulation did not become a problematic stress in the tiger.

Urine contaminations occurred in 4 out of 17 trials. Semen $\mathrm{pH}$ and the percentage of motile sperm were decreased by urine contamination $(\mathrm{P}<0.05)$ (Table 1). It was reported that sperm lose their motility completely when mixed with fresh urine [21]; however, sperm contaminated with urine showed various motilities (10 to $70 \%$ ) in the present study. This suggests that ejaculated sperm are partially protected from changes in $\mathrm{pH}$ and osmolarity by replacement of urine with Ham's F10 before electroejaculation.

Although there were large variations in the number of progressively motile sperm in each breeding season, the number tended to be increased by frequent electroejaculation in the same breeding season except for in 2007 to 2008 (Fig. 1). This result suggests that the fre-
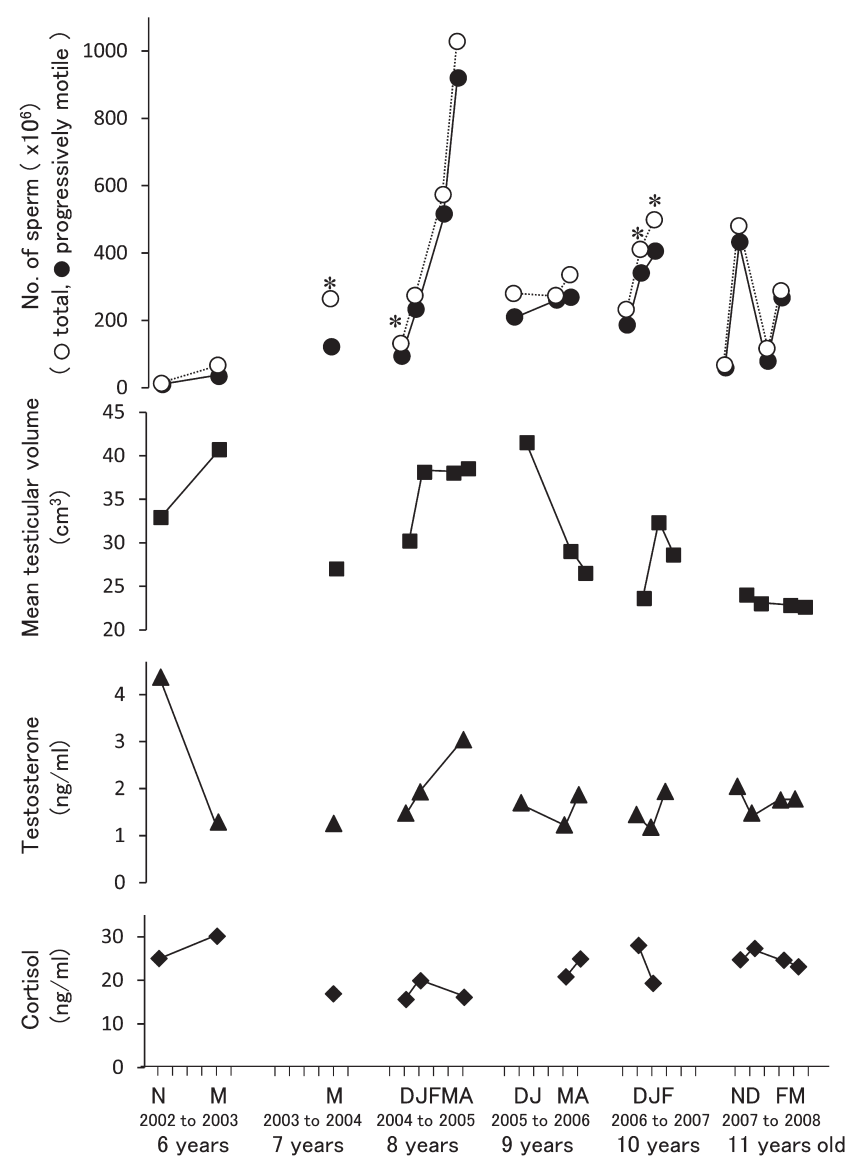

Fig. 1. Effect of frequent electroejaculation on number of sperm, testicular volume, serum testosterone and cortisol concentrations in each semen collection. *Urine contaminations were observed. N, November; D, December; J, January; F, February; M, March; A, April. 
quent electroejaculation of a male tiger in a breeding season stimulates spermatogenesis or increases the sensitivity to electroejaculation, although the reason why the numbers of sperm fluctuated in the 2007 to 2008 breeding season is not clear. In a previous study [20], the semen volume tended to increase during frequent semen collection in the cat (once a week for 2 weeks, followed by a week of rest; a total of 22 collections over 32 weeks). Pineda et al. [20] concluded this trend might indicate increase in the sensitivity of the accessory sex gland by repeated electrical stimulation, although the number of sperm was not affected $(\mathrm{P}>0.05)$. The reason for the discrepancy in sperm number between the present and previous studies is not clear. In a future study, we should examine the effect of frequent semen collection on number of sperm using other male tigers.

As shown in Fig. 2, the mean cumulative number of progressively motile sperm obtained by the fourth ejaculate was more than $200 \times 10^{6}$, which is sufficient for pregnancy by intrauterine AI in the tiger $\left(16.8 \times 10^{6}\right.$ motile sperm) [6]. Also, we speculate that $200 \times 10^{6}$ sperm can be used for intravaginal AI, since intravaginal AI with $80 \times 10^{6}$ sperm [10], tenfold the number used for successful intrauterine AI $\left(8 \times 10^{6}\right)$ [9], achieved pregnancy in the domestic cat. The sperm number in each sequential ejaculate was similar $(\mathrm{P}=0.72)$; however, the standard errors of the first and fourth ejaculates $\left(50.1 \times 10^{6}\right.$ and $76.0 \times 10^{6}$, respectively) were relatively large compared with those of the second and third ejaculates $\left(21.6 \times 10^{6}\right.$ and $6.4 \times 10^{6}$, respectively). This means that sperm were obtained constantly in the second and third ejaculates and that the most sperm were included by the fourth ejaculate. In Table 2, the relationship between timing of collection of each ejaculate and series of electrical stimuli is shown. There were only 6 out of 14 trials (42.9\%) in which fourth ejaculates were collected during three stimulus series. In the first trial of the present study, the first ejaculate of semen was not collected until performance of additional series. This suggests that frequent electrical stimuli are necessary to enhance the sensitivity to electroejaculation and that modification of electroejaculation technique may be needed depending on individual males.

In conclusion, large numbers of viable sperm from a male tiger were constantly collected by electroejaculation, and frequent semen collection (once a month for several months) may be effective for increasing the sensitivity to electrical stimuli and the number of progressively motile sperm. For effective and safe semen collection, we recommend that electroejaculation in the tiger performed up to collection of the fourth sequential ejaculate. Replacement of urine in the bladder with Ham's F10 medium before electroejaculation may decrease damage of sperm caused by urine contamination. In a future investigation with collected semen, we should study the protocol for $\mathrm{AI}$ and semen cryopreservation in the tiger.

\section{Methods}

A male mature Siberian tiger that was being kept at Asahiyama Zoological Park and Wildlife Conservation Center (Asahikawa, Japan), studbook no. 4264, and that was born in captivity in 1996 and weighed 131 to $176 \mathrm{~kg}$ was used in this study for 6 breeding seasons (2002 to 2008). This study was conducted in accordance with the Hokkaido University guidelines for the care and use of animals. The tiger was fed once daily, 2 to $4 \mathrm{~kg}$ of horse meat,

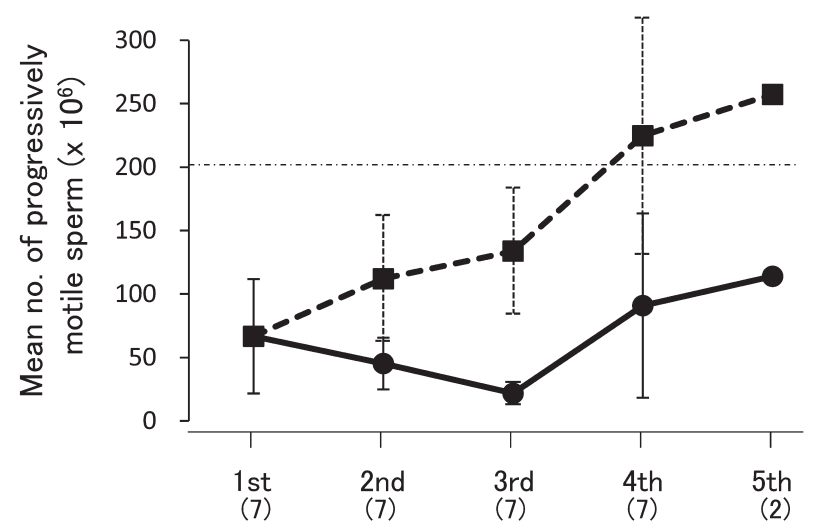

Fig. 2. Semen volume and number of progressively motile sperm in each ejaculate during electroejaculation in a Siberian tiger. The solid line shows the mean values in each ejaculate. The dashed line shows the average of cumulative values. Error bars indicate the SEM. Values in parentheses indicate the number of trials. Data for semen with urine contamination were eliminated from this analysis.

Table 2. Series of electrical stimuli* in which each ejaculate were collected

\begin{tabular}{lcccc}
\hline \multirow{2}{*}{$\begin{array}{l}\text { Ejaculates } \\
\text { (total no. of trials**) }\end{array}$} & \multicolumn{4}{c}{ No. of trials collecting each ejaculate at } \\
\cline { 2 - 5 } & $\begin{array}{c}1 \text { st } \\
\text { series }\end{array}$ & $\begin{array}{c}\text { 2nd } \\
\text { series }\end{array}$ & $\begin{array}{c}\text { 3rd } \\
\text { series }\end{array}$ & $\begin{array}{c}\text { additional } \\
\text { series }\end{array}$ \\
\hline 1st (17) & 14 & 2 & 0 & 1 \\
2nd (17) & 4 & 11 & 1 & 1 \\
3rd (16) & 1 & 6 & 4 & 5 \\
24th (14) & 0 & 4 & 2 & 8 \\
\hline
\end{tabular}

* A series was composed of more than 2 sets of 10 electrical stimuli. ** In three trials, electrical stimuli finished at second or third ejaculate, because more than $200 \times 10^{6}$ sperm were collected.

chicken and pig bone, with a fasting day every week. Water was available ad libitum. The tiger was food fasted for at least $24 \mathrm{~h}$ before each study. Water was provided up until the morning. For semen collection, the male was intramuscularly premedicated with $0.6 \mathrm{mg}$ / $\mathrm{kg}$ xylazine hydrochloride (Celactal, Bayer, Leverkusen, Germany) in the first three trials or $50 \mu \mathrm{g} / \mathrm{kg}$ medetomidine hydrochloride (Domitor, Orion, Espoo, Finland) in the other 14 trials and 0.15 $\mathrm{mg} / \mathrm{kg}$ midazolam (Dormicum, Roche, Basel, Switzerland) in a blow dart using a blowpipe. After the animal was sedated, $5 \mathrm{mg}$ / kg ketamine hydrochloride (Ketalar, Sankyo, Tokyo, Japan) was administered intramuscularly to complete anesthetic induction and immobilization. After semen collection, $100 \mu \mathrm{g} / \mathrm{kg}$ atipamezole hydrochloride (Antisedan, Orion) was administered intramuscularly to antagonize the effects of medetomidine hydrochloride. It took an average of $106 \mathrm{~min}$ from premedication to administration of the $\alpha_{2}$-adrenoceptor antagonist atipamezole after all procedures were finished. The activeness and appetite of the tiger were smoothly recovered the day after all electroejaculation trials.

Before semen collection, each testicular size (length $[\mathrm{a}] \times$ width 
[b] $\times$ height [c]) was measured with a caliper, and the testicular volume $\left(\mathrm{cm}^{3}\right)$ was calculated using a formula $(\pi / 6 \times \mathrm{a} \times \mathrm{b} \times \mathrm{c})$ [23] . The summed value for the testes was divided by 2 to provide the mean testicular volume. Bladder catheterization was performed to drain urine followed by replacement with 40-100 ml Ham's F10 medium (Invitrogen, Grand Island, NY, USA), and urine $\mathrm{pH}$ was evaluated immediately. Feces in the rectum were removed manually. A rectal ejaculatory probe $(55 \mathrm{~cm}$ long and $3.7 \mathrm{~cm}$ in diameter $)$ with three longitudinal electrodes $(125 \times 11 \mathrm{~mm})$ was used for semen collection (Fig. 3). The distance between each electrode was 10 $\mathrm{mm}$. The probe was connected to an alternatiing current, $60 \mathrm{~Hz}$ sine wave electroejaculator ( 1 channel type for mammals, Fujihira Industry, Tokyo, Japan).

Semen collection trials were performed a total of 17 times at 1- to 4-month intervals during November through April using the procedures described by a previous report [11]. Briefly, the penis was washed up with physiological saline and covered with a 50-ml polypropylene conical centrifuge tube (Becton Dickinson, Franklin Lakes, NJ, USA) that had been warmed to $37 \mathrm{C}$ in advance. The probe was lubricated with K-Y jelly (Johnson \& Johnson, New Brunswick, NJ, USA) and inserted $22 \mathrm{~cm}$ into the rectum. The probe was directed ventrally so that it would be directly over the male accessory sex glands. The electrical stimuli were applied basically as 3 series in a 3 -sec-on/3-sec-off pattern using 3 to $6 \mathrm{~V}$; 30 ( 10 stimulations at 3,4 and $5 \mathrm{~V}$ : first series), 30 (10 stimulations at 4, 5 and $6 \mathrm{~V}$ : second series), and 20 stimuli (10 stimulations at 5 and $6 \mathrm{~V}$ : third series), and a 3 -min rest was permitted between each series as previously described $[5,11]$. In the present study, to prevent urine contamination and clarify the characteristics of each ejaculate, the conical tube was replaced with a new tube when semen was ejaculated during 10 stimuli with the same voltage. In seven out of 17 trials, the total and motile sperm numbers in each ejaculate were counted, and these data were used for the analysis of sperm number dynamics in sequential ejaculates. In other trials, the volume of each ejaculate was checked, and numbers of sperm were evaluated after mixing some ejaculates. If the number of collected sperm was low after the 3-stimulus series, additional series of 10 to 50 electrical stimuli (4 to $6 \mathrm{~V}$ ) were performed. Collected semen was subjected to evaluation of its characteristics immediately after collection. When semen was contaminated with urine, the samples with and without contamination were evaluated separately. The sperm concentration was calculated by a hemacytometer. The percentage of progressively motile sperm was assessed microscopically as described previously [11]. The viability of sperm was assessed using an eosin-nigrosin staining method [24]. Sperm morphology was evaluated after fixing in $2.5 \%$ glutaraldehyde followed by staining with $3 \%$ Giemsa's solution. For calculating the viability and morphological normality of sperm, more than 200 sperm per slide were observed.

Blood samples were collected into vacutainer glass tube by femoral vein venipuncture, and serum was separated by centrifugation and stored at $-80 \mathrm{C}$ until assayed. Serum testosterone and cortisol were measured with a chemiluminescence immunoassay method as described previously [25].

The data were statistically analyzed using software (JMP version 8 , SAS Institute, Cary, NC, USA). The numbers of total and motile sperm in each ejaculates were compared by one-way analysis of

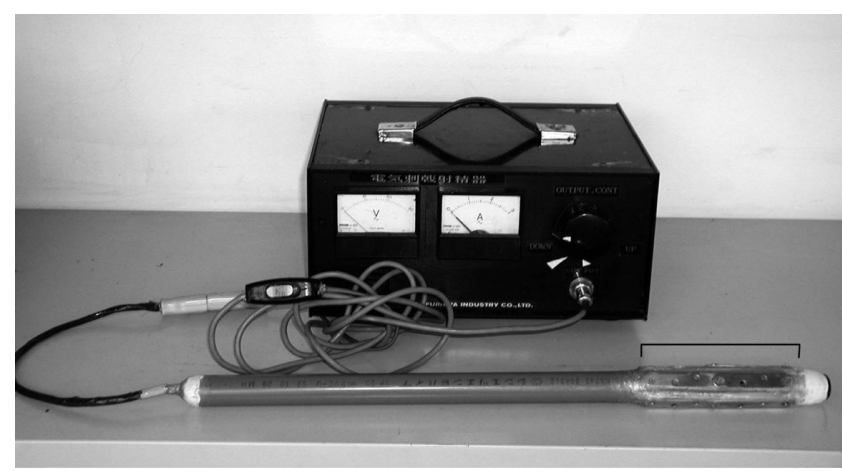

Fig. 3. The electroejaculator and rectal ejaculatory probe with three longitudinal electrodes.

variance. The characteristics of semen with and without urine contamination were compared by Student's $t$-test or Welch's $t$-test after examining the equality of variances using the F-test.

\section{Acknowledgments}

We wish to thank staffs of Asahiyama Zoological Park \& Wildlife Conservation Center, Sapporo Maruyama Zoo, Noboribetsu Bear Park, Kushiro Zoo, Obihiro Zoo, Hokkaido University, and Obihiro University of Agriculture and Veterinary Medicine for their kind help and advice. This study was supported by Grantsin-Aid for Scientific Research (No. 17780206) from the Ministry of Education, Culture, Sports, Science and Technology of Japan to $\mathrm{MN}$ and by research grants from the Japanese Association of Zoos and Aquariums and Northern Advancement Center for Science \& Technology to YT.

\section{References}

1. Miquelle D, Darman Y, Seryodkin I. Panthera tigris ssp. altaica., IUCN Red List of Threatened Species. Version 2011.2. Switzerland: IUCN; 2011.

2. Mülller P. International Tiger Studbook. Leipzig: Zoologischer Gardens Leipzig; 2009.

3. Pukazhenthi BS, Wildt DE. Which reproductive technologies are most relevant to studying, managing and conserving wildlife? Reprod Fertil Dev 2004; 16: 33-46. [Medline]

4. Graham LH, Byers AP, Armstrong DL, Loskutoff NM, Swanson WF, Wildt DE, Brown JL. Natural and gonadotropin-induced ovarian activity in tigers (Panthera tigris) assessed by fecal steroid analyses. Gen Comp Endocrinol 2006; 147: 362-370. [Medline]

5. Wildt DE, Phillips LG, Simmons LG, Goodrowe KL, Howard JG, Brown JL, Bush M. Seminal-endocrine characteristics of the tiger and the potential for artificial breeding. In: Tilson RL,Seal US (eds), Tigers of the World: The Biology, Biopolitics, Management and Conservation of an Endangered Species. Park Ridge: Noyes Publications; 1987: 255-279.

6. Donoghue AM, Johnston LA, Armstrong DL, Simmons LG, Wildt DE. Birth of a siberian tiger cub (Panthera tigris altaica) following laparoscopic intrauterine artificial insemination. J Zoo Wildl Med 1993; 24: 185-189.

7. Armstrong D. Tiger cub born by artificial insemination at Omaha. In: Swanson WF, Flecthall N (eds), North American Felid Taxon Advisory Group (TAG) 2004 Annual Report and Action Plan.: Published online at Felid TAG official website (www.felidtag. org), 2004: 72-73.

8. Chagas e Silva JN, Leitão RM, Lapão NE, da Cunha MB, da Cunha TP, da Silva JP, Paisana FC. Birth of Siberian tiger (Panthera tigris altaica) cubs after transvaginal artificial insemination. J Zoo Wildl Med 2000; 31: 566-569. [Medline]

9. Tsutsui T, Tanaka A, Takagi Y, Nakagawa K, Fujimoto Y, Murai M, Anzai M, Hori T. Unilateral intrauterine horn insemination of fresh semen in cats. J Vet Med Sci 2000; 62 
1241-1245. [Medline]

10. Tanaka A, Takagi Y, Nakagawa K, Fujimoto Y, Hori T, Tsutsui T. Artificial intravaginal insemination using fresh semen in cats. J Vet Med Sci 2000; 62: 1163-1167. [Medline]

11. Howard JG. Semen collection and analysis in carnivores. In: Fowler ME (ed), Zoo and Wild Animal Medicine: Current Therapy 3. Philadelphia: W. B. Saunders; 1993: 390-399.

12. Byers AP, Hunter AG, Seal US, Binczik GA, Graham EF, Reindl NJ, Tilson RL. In-vitro induction of capacitation of fresh and frozen spermatozoa of the Siberian tiger (Panthera tigris). J Reprod Fertil 1989; 86: 599-607. [Medline]

13. Byers AP, Hunter AG, Seal US, Graham EF, Tilson RL. Effect of season on seminal traits and serum hormone concentrations in captive male Siberian tigers (Panthera tigris). J Reprod Fertil 1990; 90: 119-125. [Medline]

14. Donoghue AM, Byers AP, Johnston LA, Armstrong DL, Wildt DE. Timing of ovulation after gonadotrophin induction and its importance to successful intrauterine insemination in the tiger (Panthera tigris). J Reprod Fertil 1996; 107: 53-58. [Medline]

15. Donoghue AM, Johnston LA, Seal US, Armstrong DL, Simmons LG, Gross T, Tilson RL, Wildt DE. Ability of thawed tiger (Panthera tigris) spermatozoa to fertilize conspecific eggs and bind and penetrate domestic cat eggs in vitro. J Reprod Fertil 1992; 96: 555-564. [Medline]

16. Donoghue AM, Johnston LA, Seal US, Armstrong DL, Tilson RL, Wolf P, Petrini K, Simmons LG, Gross T, Wildt DE. In vitro fertilization and embryo development in vitro and in vivo in the tiger (Panthera tigris). Biol Reprod 1990; 43: 733-744. [Medline]

17. Shivaji S, Jayaprakash D, Patil SB. Assessment of inbreeding depression in big cats: Testosterone levels and semen analysis. Curr Sci 1998; 75: 923-930.

18. Shivaji S, Kholkute SD, Verma SK, Gaur A, Umapathy G, Singh A, Sontakke S, Shailaja K, Reddy A, Monika S, Sivaram V, Jyotsna B, Bala S, Ahmed MS, Bala
A, Chandrashekar BV, Gupta S, Prakash S, Singh L. Conservation of wild animals by assisted reproduction and molecular marker technology. Indian J Exp Biol 2003; 41: 710-723. [Medline]

19. Pineda MH, Dooley MP. Effects of voltage and order of voltage application on seminal characteristics of electroejaculates of the domestic cat. Am J Vet Res 1984; 45: 1520-1525. [Medline]

20. Pineda MH, Dooley MP, Martin PA. Long-term study on the effects of electroejaculation on seminal characteristics of the domestic cat. Am J Vet Res 1984; 45: 1038-1041. [Medline]

21. Makler A, David R, Blumenfeld Z, Better OS. Factors affecting sperm motility. VII. Sperm viability as affected by change of $\mathrm{pH}$ and osmolarity of semen and urine specimens. Fertil Steril 1981; 36: 507-511. [Medline]

22. Wildt DE, Phillips LG, Simmons LG, Chakraborty PK, Brown JL, Howard JG, Teare A, Bush M. A comparative analysis of ejaculate and hormonal characteristics of the captive male cheetah, tiger, leopard, and puma. Biol Reprod 1988; 38: 245-255. [Medline]

23. Goede J, Weijerman ME, Broers CJ, de Winter JP, van der Voort-Doedens LM, Hack WW. Testicular volume and testicular microlithiasis in boys with Down syndrome. J Urol 2012; 187: 1012-1017. [Medline]

24. Ishikawa A, Matsui M, Tsuruga H, Sakamoto H, Takahashi Y, Kanagawa H. Electroejaculation and semen characteristics of the captive Hokkaido brown bear (Ursus arctos yesoensis). J Vet Med Sci 1998; 60: 965-968. [Medline]

25. Blackburn GF, Shah HP, Kenten JH, Leland J, Kamin RA, Link J, Peterman J, Powell MJ, Shah A, Talley DB, Tayagi SK, Wilkins E, Wu TG, Massey RJ. Electrochemiluminescence detection for development of immunoassays and DNA probe assays for clinical diagnostics. Clin Chem 1991; 37: 1534-1539. [Medline] 